\title{
ERRATUM
}

\section{Variable telomere length across post-mortem human brain regions and specific reduction in the hippocampus of major depressive disorder}

F Mamdani, B Rollins, L Morgan, RM Myers, JD Barchas, AF Schatzberg, SJ Watson, H Akil, SG Potkin, WE Bunney, MP Vawter and PA Sequeira

Translational Psychiatry (2016) 6, e969; doi:10.1038/tp.2015.164; published online 6 December 2016

Correction to: Translational Psychiatry (2015) 5, e636; doi:10.1038/ tp.2015.134; published online 15 September 2015

In the Acknowledgments section, the funding through The Brain \& Behavior Research Foundation (formerly NARSAD) Young
Investigator Award and by NIMH research grant R01MH097082 was incorrectly attributed. The funding was provided to PA Sequeira. The publisher regrets this error. 